\title{
The Effectiveness of Food Insecurity Screening in Pediatric Primary Care
}

\author{
Wendy Gwirtzman Lane ${ }^{1,2,}$, Howard Dubowitz ${ }^{1}$, Susan Feigelman ${ }^{1}$ and Gina Poole ${ }^{1}$ \\ ${ }^{1}$ Department of Pediatrics, University of Maryland School of Medicine, Center for Families, 520 W. Lombard \\ St., Baltimore, MD 21201, USA \\ ${ }^{2}$ Department of Epidemiology and Public Health, University of Maryland School of Medicine, 660 West \\ Redwood St., Baltimore, MD 21201, USA
}

\begin{abstract}
Background: Food insecure children are at increased risk for medical and developmental problems. Effective screening and intervention are needed.

Methods: Our purpose was to (1) evaluate the validity and stability of a single item food insecurity (FI) screen. (2) Assess whether use may lead to decreased FI. Part of a larger cluster randomized controlled trial, pediatric residents were assigned to SEEK or control groups. A single FI question (part of a larger questionnaire) was used on SEEK days. SEEK residents learned to screen, assess, and address FI. A subset of SEEK and control clinic parents was recruited for the evaluation. Parents completed the USDA Food Security Scale ("gold standard"), upon recruitment and 6-months later. Validity, positive and negative predictive values (PPV, NPV) was calculated. The proportion of screened families with initial and subsequent FI was measured. Screening effectiveness was evaluated by comparing SEEK and control screening rates and receipt of Supplemental Nutrition Assistance Program (SNAP) benefits between initial and 6-month assessments.

Results: FI screen stability indicated substantial agreement (Cohen's kappa $=0.69$ ). Sensitivity and specificity was $59 \%$ and $87 \%$, respectively. The PPV was $70 \%$; NPV was $81 \%$. SEEK families had a larger increase in screening rates than control families $(24 \%$ vs. $4.1 \%, p<0.01)$. SEEK families were more likely to maintain SNAP enrollment $(97 \%$ vs. $81 \%$, $\mathrm{p}=0.05$ ). FI rates remained stable at approximately $30 \%$ for both groups.
\end{abstract}

Conclusions: A single question screen can identify many families with $\mathrm{FI}$, and may help maintain food program enrollment. Screening may not be adequate to alleviate FI.

Keywords: Hunger, children, screening, primary care, intervention, food insecurity.

\section{BACKGROUND}

Food security is defined as having access, at all times, to provide enough food for an active, healthy life [1]. Food insecurity (FI) occurs when nutritionally adequate food is unavailable, or its availability is limited or uncertain. Approximately $21 \%$ of U.S. households with children were food insecure in 2011 [2].

FI impairs children's health and well-being. Children who are food insecure have a higher frequency of acute and chronic illnesses and hospitalizations compared to food secure children [3-5]. They are also at higher risk for developmental delay, learning difficulties, attachment problems, depression, and both internalizing and externalizing behavioral problems [610]. Pregnant women who are food insecure are more likely to have infants with birth defects and low birth weight $[11,12]$.

Because of their frequent contact with young children, pediatricians are uniquely positioned to

${ }^{*}$ Address correspondence to this author at the Department of Epidemiology and Public Health, 660 W. Redwood St., Baltimore, MD 21201, USA; Tel: (410) 706-7865; Fax: (410) 706-8013; E-mail: wlane@epi.umaryland.edu identify and help address FI. However, time with children and families is limited. Without brief, effective screening tools, pediatricians may be reluctant to screen families for FI. The objective of this study was to evaluate the validity and stability of a single question on $\mathrm{FI}$ in the SEEK Parent Screening Questionnaire (PSQ), and to assess whether its use reduced the rate of $\mathrm{FI}$.

\section{METHODS}

\section{Context and Setting}

The evaluation of this single item FI screen was part of the SEEK I study, a randomized controlled trial conducted in a pediatric resident continuity clinic serving urban, low income children [13]. The objectives of SEEK were to teach pediatric residents to screen for child maltreatment risk factors using a standardized screening tool (the Parent Screening Questionnaire, or PSQ); to briefly assess positive screens; and to provide brief interventions such as information on community resources, social work referral, and/or motivational interviewing for behavior change.

Resident clinic days were randomized by coin toss to be either SEEK (Intervention) days or usual care 
(Control) days. Residents assigned to clinics on SEEK days were trained to screen for, assess, and provide initial management of $\mathrm{FI}$. FI interventions included providing information on how to apply for Supplemental Nutrition Assistance Program (SNAP, formerly food stamps) benefits and other federal food assistance programs, and providing information about local food resources such as food pantries. Screening on SEEK days was standardized using the Parent Screening Questionnaire (PSQ), discussed below. Families with pediatricians in the control group received routine wellchild care.

\section{Sample}

We recruited a subset of parents from each group to evaluate the model. Parents who brought their children under age 6 to the resident continuity clinic for a checkup were eligible to participate. Parents were excluded if they had another child in the study or if the child was in foster care. Because the clinic population was nearly all English speaking, the PSQ was not translated into other languages, and we excluded nonEnglish speakers. A research assistant approached eligible parents assigned to both SEEK and control clinic days to explain the study. If interested, informed consent was obtained following procedures approved by the University's Human Subjects Review Committee. Parent recruitment took place over approximately 18 months. This meant that many parents had been exposed to the SEEK model before being recruited, and the initial data therefore represent early outcomes rather than true baseline.

\section{SEEK Evaluation}

All parents of children under 6 years of age assigned to SEEK clinic days were asked to complete the PSQ while waiting for their child's checkup. Parents recruited for the evaluation from both SEEK and control clinics were scheduled to return within two weeks to complete a self-administered computerized interview in our laboratory. The interview included computerized versions of: (1) the PSQ (hereafter referred to as the Lab PSQ) to determine questionnaire stability; and (2) the Food Security Scale (FSS), [14-17] a comprehensive, standardized $\mathrm{FI}$ measure, to examine validity of the screening question.

Six months after their initial laboratory visit, recruited parents returned to the laboratory and completed the Lab PSQ and FSS to evaluate the effectiveness of SEEK. Medical record reviews were performed by a trained medical student who reviewed records of children in recruited families for evidence of FI screening. FI screening was considered to have occurred if a completed SEEK PSQ was in the chart or there were notations about $\mathrm{FI}$ screening in the clinic visit note. Because the PSQ was only present in the records of SEEK group children, the student could not be blinded to study group assignment. Bias was minimized through the development and use of a standard data abstraction tool with a set of decision rules.

\section{Screening Questionnaire}

The SEEK Parent Screening Questionnaire (PSQ) is a 1-page paper and pencil questionnaire developed to screen parents for child maltreatment risk factors, including $\mathrm{FI}$, during routine well child care. A brief introduction framed the questions in a supportive manner. All questions had yes/no responses. The SEEK project and PSQ have been described in detail elsewhere [13, 18-23]. The full SEEK questionnaire in English, Spanish, and Chinese is available at: http://theinstitute.umaryland.edu/seek/seek_psq.cfm

The PSQ FI question was developed through a review of validated screening measures [24,25]. After pilot testing, the single item selected was "In the last year, did you worry that your food would run out before you got money or food stamps to buy more?" This question came directly from the U.S. Department of Agriculture Food Security Scale [14].

\section{Validation of the PSQ}

\section{Validation Measure}

The U.S. Department of Agriculture's Food Security Scale (FSS) is an 18-item measure designed to assess $\mathrm{FI}$ and hunger in the U.S [14]. We used the Guide to Implementing the Core Food Security Module, Revised to measure FI [15]. Respondents indicated whether they experienced any of 18 situations in the past year. According to the USDA, a family is food insecure if there are three or more affirmative responses. The reliability and validity of the FSS have been demonstrated $[16,17]$.

\section{Data Analysis}

Sample sizes were calculated for the primary study outcome: reduction in incidence of child maltreatment. They were not conducted for secondary outcomes such as retention of SNAP benefits or reduction in FI. All analyses were conducted using SAS version 8.1 (Cary, 
NC). All study procedures were reviewed and approved by our institutional IRB.

Only data from SEEK parents were used to assess PSQ stability and validity, because control parents did not complete the PSQ in the pediatric clinic. These analyses were limited to the 205 parents who returned to complete the Lab PSQ and FSS within two weeks of completion of the Clinic PSQ (Figure 1).

\section{Stability}

Because the PSQ completion method changed from paper (in the clinic) to computer (in the lab), we were unable to determine test-retest reliability. Instead, we examined the measure's stability by comparing the FI question on the clinic PSQ to the Lab PSQ using Cohen's Kappa [26]. Kappa values range from -1 to 1 , with values of $<0.21$ implying no to slight agreement, $0.21-0.6$ implying fair to moderate agreement, and values $>0.6$ implying substantial to perfect agreement.

\section{Validity}

To determine the validity of the clinic FI screen we calculated the sensitivity, specificity, positive (PPV) and negative predictive values (NPV), and likelihood ratios by comparing the Clinic PSQ question to the FSS.

\section{Screening Effectiveness}

Effectiveness of screening was examined in three ways:

(1) The rates of screening, assessment (additional questions to clarify), and action (recommendations and referrals) taken for parents in SEEK clinics were compared to those assigned to control clinics. To determine whether the screening rates for SEEK parents increased more than for control parents, mean rates of screening during well child visits for SEEK and control parents were calculated, and the changes in these rates were compared. (2) The rates of FI by Lab PSQ and by FSS were calculated initially and at 6month follow-up. P-values for the rate difference between SEEK and control groups at each time period were calculated using chi-square analyses. The analyses were limited to parents with data both initially and 6 months later ( $\mathrm{N}=419$ for Lab PSQ; $\mathrm{N}=384$ for FSS; Figure 1). (3) Among families with FI initially, rates of Supplemental Nutrition Assistance Program

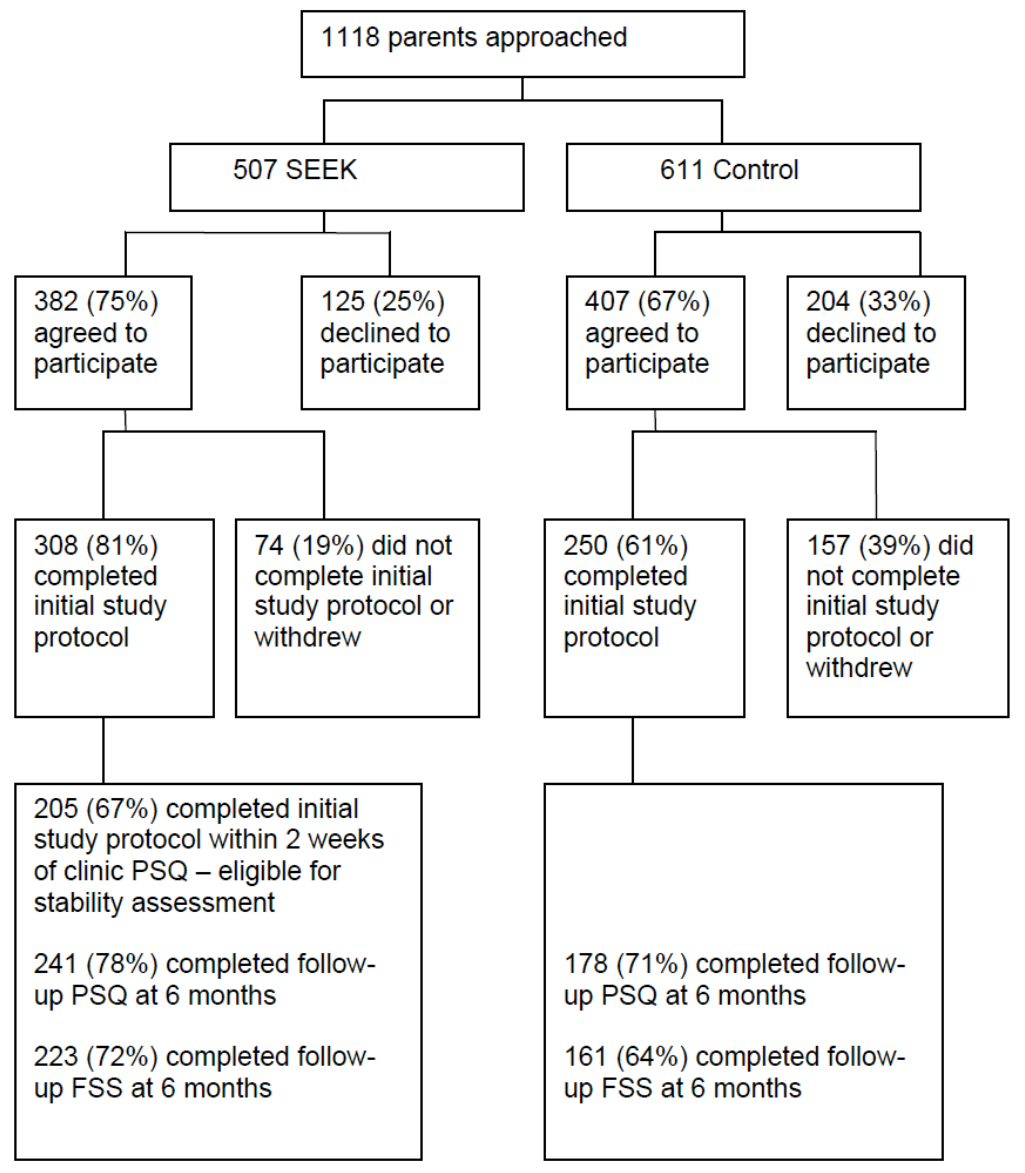

Figure 1: Algorithm of Families Recruited. 
(SNAP, formerly called food stamps) receipt for SEEK and control groups were calculated. Rates at initial and 6-month assessments were compared by chi-square analysis to assess changes in SNAP receipt between SEEK and control parents. Data for this analysis were limited to the 63 parents with $\mathrm{FI}$ at baseline who completed the FSS and questions about SNAP receipt at both time points.

\section{RESULTS}

\section{Participant Demographics}

More than $90 \%$ of caregiver participants were mothers. Caregivers were predominantly AfricanAmerican, and unmarried. Approximately one-third were employed. There were few statistically significant differences in demographics between the SEEK and control groups (Table 1). The median age of SEEK children was slightly younger than control children (6 vs. 8 months, $p=0.03$ ), and SEEK families had fewer children living in the home (mean 2.2 children for SEEK vs. 2.5 for control, $p=0.04$ ).

\section{Screen Stability and Validity}

The stability of the $\mathrm{FI}$ screening question, as measured with Cohen's kappa was 0.69, indicating substantial agreement between the Clinic PSQ and the Lab PSQ. The sensitivity and specificity of the screening question were $59 \%$ and $87 \%$, respectively (Table 2). The positive predictive value of the screen was $70 \%$, indicating that families with a positive screen had a $70 \%$ likelihood of having $\mathrm{FI}$. The negative predictive value was $81 \%$, indicating that families with a negative screen had an $81 \%$ likelihood of not having $\mathrm{FI}$ (i.e. they were food secure). Positive and negative likelihood ratios were 4.5 and 0.47 , respectively. This

Table 1: Demographic Characteristics of the SEEK and Control Group Families at the Time of Entry ( $N=558)$

\begin{tabular}{|c|c|c|c|}
\hline & $\begin{array}{l}\text { SEEK Families } \\
\qquad(\mathrm{N}=308)\end{array}$ & $\begin{array}{l}\text { Control Families } \\
\qquad(\mathrm{N}=250)\end{array}$ & $\mathbf{P}$ \\
\hline \multicolumn{4}{|l|}{ Child } \\
\hline Age (months), median $\left(\mathrm{IQR}^{\S}\right)^{*}$ & $6.0(13)$ & $8.0(17)$ & .03 \\
\hline African-American, N (\%) & $285(93)$ & $234(94)$ & .74 \\
\hline Female, N (\%) & $143(46)$ & $127(51)$ & .30 \\
\hline \multicolumn{4}{|l|}{ Parent } \\
\hline Age (years), mean (SD) & $25.3(6.8)$ & $25.3(7.3)$ & .94 \\
\hline Caregiver relationship, $\mathrm{N}(\%)$ & & & .47 \\
\hline Mother & $287(93)$ & $231(92)$ & \\
\hline Father & $13(4)$ & $15(6)$ & \\
\hline Other & $8(3)$ & $4(2)$ & \\
\hline Marital status, N (\%) & & & .98 \\
\hline Single & $268(87)$ & $216(86)$ & \\
\hline Married & $26(8)$ & $22(9)$ & \\
\hline Separated/Divorced/Widowed & $14(5)$ & $12(5)$ & \\
\hline Education, N (\%) & & & .11 \\
\hline$<$ High school & $112(36)$ & $104(42)$ & \\
\hline HS or GED & $111(36)$ & $96(38)$ & \\
\hline At least some college & $85(28)$ & $50(20)$ & \\
\hline Employed, N (\%) & $95(32)$ & $86(35)$ & .47 \\
\hline \multicolumn{4}{|l|}{ Family } \\
\hline \# of children in home, mean (SD) & $2.2(1.4)$ & $2.5(1.4)$ & .04 \\
\hline \# of adults in home, mean (SD) & $2.2(1.2)$ & $2.2(1.1)$ & .65 \\
\hline Medical Assistance, ${ }^{\complement} \mathrm{N}(\%)$ & $270(93)$ & $224(92)$ & .78 \\
\hline
\end{tabular}

${ }^{*} \mathrm{p}<0.05$. 
Table 2: Sensitivity, Specificity, Predictive Values and Likelihood Ratios for the Clinic PSQ Food Insecurity Question Compared with the USDA Food Security Scale (FSS) $(\mathrm{N}=205)^{\mathrm{a}}$

\begin{tabular}{|c|c|c|c|c|c|c|}
\hline Food Insecurity Question & $\begin{array}{l}\text { Sensitivity } \\
\text { (\%) }\end{array}$ & $\begin{array}{l}\text { Specificity } \\
\text { (\%) }\end{array}$ & $\begin{array}{l}\text { PPV } \\
(\%)\end{array}$ & $\begin{array}{l}\text { NPV } \\
(\%)\end{array}$ & LR+ & LR- \\
\hline $\begin{array}{l}\text { 'In the last year, did you worry that your food } \\
\text { would run out before you got money or food } \\
\text { stamps to buy more?' }\end{array}$ & 59 & 87 & 70 & 81 & 4.5 & 0.47 \\
\hline
\end{tabular}

${ }^{a}$ Families were classified as food Insecure if the number of affirmative responses to the 18 items on the FSS $>2$. The PSQ was completed by SEEK parents in the pediatric clinic. The FSS was completed by 205 SEEK parents in the laboratory within 2 weeks of completing the clinic PSQ.

LR- = Negative Likelihood Ratio; LR + = Positive Likelihood Ratio; NPV = Negative Pedictive Value; PPV = Positive Predictive Value

indicates that families with FI were 4.5 times more likely to have a positive screen than those without $\mathrm{FI}$, and those without FI were about half as likely to screen positive than those with $\mathrm{Fl}$.

\section{Screen Effectiveness}

\section{Rates of Screening, Assessment, and Action}

Before SEEK was implemented, the proportion of families screened for $\mathrm{FI}$ was quite low $-14.5 \%$ in the SEEK group and $4.5 \%$ in the control group (Table 3 ). After the implementation of SEEK, screening rates went up in both groups - to $87.5 \%$ in the SEEK group but only to $11.9 \%$ in the control group $(p<0.01)$. Among a subset of families with at least 2 well child visits prior to SEEK, the average rate of screening increased more in the SEEK group relative to the control group (24\% vs. $4 \%$ increase, $p<0.01$ ) (Data not shown).

When a screen was positive, the problem was usually assessed, and action was taken (Table 3 ). Following implementation of SEEK, SEEK parents were significantly more likely to have $\mathrm{FI}$ identified and addressed compared to parents in the control group (16.9\% vs. $2.9 \%$ of all participating families; $p<0.01$ ).

\section{Change in Rates of FI Over Time}

There was no significant difference in FI rates - by the Lab PSQ or the FSS - between the SEEK and control families either before or after implementing SEEK (Table 4). Of the 223 SEEK parents providing initial and follow-up data, $73(32.7 \%)$ met criteria for $\mathrm{FI}$ on the FSS initially, and 66 (29.6\%) met criteria 6 months later. Among the 161 control parents, 50 (31.1\%) met FI criteria initially, and 48 (29.8\%) did so 6 months later.

\section{Change in Rate of SNAP Benefits Receipt}

123 Families (73 SEEK and 50 control) met criteria for $\mathrm{FI}$ at time 1, and 63 (32 SEEK and 31 control) of these families provided information about SNAP benefits receipt at both time periods. There was no significant difference in the percentage receiving SNAP benefits at time 1 (96.9\% of SEEK vs. $100 \%$ of control). However, while almost all SEEK families maintained their SNAP enrollment, 20 percent of control families were no longer enrolled at 6-month follow-up [31/32 (96.9\%) vs. $25 / 31$ (80.6\%); $p=0.05]$ (Table 5).

Table 3: Rate of Food Insecurity Screening and Follow-Up Action by SEEK and Control Residents Before and During Implementation of the SEEK Model ${ }^{\mathrm{a}}$

\begin{tabular}{|c|c|c|c|c|c|c|c|c|c|}
\hline \multirow[t]{2}{*}{ Period } & \multirow[t]{2}{*}{ Group } & \multicolumn{2}{|c|}{ Screened } & \multicolumn{2}{|c|}{ Screened Positive } & \multicolumn{2}{|r|}{ Assessed } & \multicolumn{2}{|c|}{$\begin{array}{l}\text { Problem Found and } \\
\text { Action Taken }\end{array}$} \\
\hline & & $\mathbf{N}$ & $\%$ & $\mathbf{N}$ & $\%$ out of total ${ }^{b}$ & $\mathbf{N}$ & $\%$ out of total ${ }^{b}$ & $\mathbf{N}$ & $\%$ out of total ${ }^{b}$ \\
\hline \multirow{2}{*}{ Before } & $\begin{array}{l}\text { SEEK } \\
\mathrm{N}=69\end{array}$ & 10 & 14.5 & 4 & 5.8 & 3 & 4.3 & 3 & 4.3 \\
\hline & $\begin{array}{c}\text { Control } \\
\mathrm{N}=67\end{array}$ & 3 & 4.5 & 2 & 3.0 & 2 & 3.0 & 2 & 3.0 \\
\hline \multirow{2}{*}{ After } & $\begin{array}{c}\text { SEEK } \\
\mathrm{N}=296\end{array}$ & 259 & 87.5 & 83 & 28.0 & 53 & 17.9 & 50 & 16.9 \\
\hline & $\begin{array}{l}\text { Control } \\
\mathrm{N}=243\end{array}$ & 29 & $11.9^{*}$ & 11 & $4.5^{*}$ & 7 & $2.9^{*}$ & 7 & $2.9^{*}$ \\
\hline
\end{tabular}

${ }^{\mathrm{a}}$ Data Obtained by Chart Review; All analyses based on original group assignment.

${ }^{b}$ Percentages of families where screening, assessment, or action was performed, among all participants whose child's medical chart was available.

${ }^{*} \mathrm{P}<.01$ by chi square test for the difference between SEEK and control groups. 
Table 4: Rates of Food Insecurity Identified on SEEK PSQ, and on FSS at Initial and Follow-up Assessments ${ }^{a}$

\begin{tabular}{|c|c|c|c|c|}
\hline & Timing of Assessment & $\begin{array}{l}\text { SEEK } \\
\mathrm{N}(\%)\end{array}$ & $\begin{array}{c}\text { Control } \\
\text { N (\%) }\end{array}$ & $p$-value ${ }^{b}$ \\
\hline \multirow{2}{*}{$\begin{array}{c}\text { PSQ } \\
\mathrm{N}=419^{c}\end{array}$} & Initial & $88 / 241(36.5 \%)$ & $76 / 178(42.7 \%)$ & 0.2 \\
\hline & 6-month follow-up & $75 / 241(31.1 \%)$ & $50 / 178(28.1 \%)$ & 0.5 \\
\hline \multirow{2}{*}{$\begin{array}{c}\text { FSS } \\
\mathrm{N}=384^{\mathrm{d}}\end{array}$} & Initial & 73/223 (32.7\%) & $50 / 161(31.1 \%)$ & 0.7 \\
\hline & 6-month follow-up & $66 / 223(29.6 \%)$ & $48 / 161(29.8 \%)$ & 0.9 \\
\hline
\end{tabular}

${ }^{a}$ Data includes only participants who completed PSQs initially and at the 6-month follow-up; All analyses based on original group assignment.

${ }^{b}$ All p-values are comparisons of SEEK to control group.

${ }^{\mathrm{C}} \mathrm{N}=241$ for the SEEK group and $\mathrm{N}=178$ for the control group.

${ }^{\mathrm{d}} \mathrm{N}=223$ for the SEEK group and $\mathrm{N}=161$ for the control group.

FSS = USDA Food Security Scale; PSQ = Parent Screening Questionnaire.

Table 5: SNAP Benefit Receipt at 6-month Follow-up Among SEEK and Control Families Who Met Criteria for Food Insecurity by FSS at Initial Assessment ${ }^{\mathrm{a}}$

\begin{tabular}{|c|c|c|}
\hline $\begin{array}{c}\text { SNAP Benefit Receipt } \\
\text { at 6-month Follow-up }\end{array}$ & $\begin{array}{c}\text { SEEK } \\
\text { N (column \%) }\end{array}$ & $\begin{array}{c}\text { Control } \\
\text { N (column \%) }\end{array}$ \\
\hline \hline Not Receiving SNAP & $1(3.1 \%)$ & $6(19.4 \%)$ \\
\hline Receiving SNAP & $31(96.9 \%)$ & $25(80.6 \%)$ \\
\hline
\end{tabular}

${ }^{a} 123$ families met criteria for food insecurity at initial assessment. Data on SNAP benefit receipt was provided by 63 parents. P-value by 2 -sided Fisher's Exact test $=$ 0.05 .

FSS = USDA Food Security Scale; SNAP = Supplemental Nutrition Assistance Program

\section{DISCUSSION}

Food insecurity is, unfortunately, a common problem, affecting about 1 in 5 children in the U.S. Pediatricians and other child health providers will encounter children and families with food insecurity. However, because most children with FI have normal growth parameters $[27,28]$, they won't be identified by child health providers unless families are specifically asked about FI.

Our data demonstrate that using a single question screen in a primary care setting can effectively identify families with $\mathrm{FI}$. In addition, the SEEK model, including the $P S Q$, increased both the rate of screening and the rate of $\mathrm{Fl}$ intervention when compared to routine care without standardized screening. Our study is not the first study to demonstrate that brief screens can identify FI $[24,25]$. However, ours is the first to show that screening may help families maintain enrollment in food assistance programs. Unfortunately, this improvement was not enough to lessen Fl.

Other authors have developed FI screening questionnaires for the pediatric primary care setting. Kleinman, et al. used a single item FI screen: "In the past month, was there any day when you or anyone in your family went hungry because you did not have enough money for food?" [24]. This question had $83 \%$ sensitivity and $80 \%$ specificity for identifying food insecure families. Hager and colleagues assessed the validity of a 2-item screen, using the first two questions from the FSS [25]. Respondents completed the screening and gold standard questions in a pediatric clinic. However, the responses were not shared with the primary care provider. An affirmative response to either one of these questions had a sensitivity of $97 \%$ and a specificity of $83 \%$. Limiting the screening to the same FSS question that was included in the $P S Q$ provided a sensitivity of $93 \%$ and a specificity of $85 \%$. It is possible that the lower sensitivity of our screen was due to our method of validation; we used the actual questionnaire from the clinical setting, where some families may have been reluctant or embarrassed to disclose $\mathrm{FI}$ to their child's doctor. Our positive predictive value of $70 \%$ was slightly higher than the $62 \%$ positive predictive value in the Hager study, reflecting the lower prevalence of $\mathrm{FI}$ in their sample (23\% vs. $34 \%)$.

Regardless of how well screening tests perform, a vital factor in determining whether to recommend routine screening is whether screening leads to positive outcomes for children and families. Our data demonstrate that systematic screening increases the likelihood that families with FI will be referred for services. The data also suggest that systematic 
screening can increase the likelihood that families will maintain enrollment in the SNAP benefits program.

Unfortunately, while systematic screening was associated with maintenance of SNAP enrollment, it was not associated with increased food security among participating families. These findings suggest that SNAP benefits may not be adequate to eliminate $\mathrm{FI}$. While a number of studies have shown that government assistance programs can reduce $\mathrm{FI}$ and improve child health, [29-32] studies have also indicated that SNAP benefits generally are not adequate to support an entire family's nutritional needs, [33-35] and may not fully eliminate FI in some families.

An advantage of the SEEK PSQ over other brief FI screens is that it also addresses other prevalent family risk factors, including depression and intimate partner violence $[13,18,20]$. Because children living in families with intimate partner violence or maternal depression are less likely to receive nutrition assistance, [36] screening for all of these family risk factors may increase the likelihood that food insecure families are able to access services.

There were a number of limitations to our study. First, our FI screen was validated in a clinic with a very high prevalence of both poverty and FI. Therefore, the utility of implementing screening in practices serving primarily middle income families is unclear. This validation study was limited to families with young children; the validity in families with older children has not been established. Because the SEEK families were recruited over an extended period of time, we do not have baseline data to determine whether the two groups had similar rates of food security prior to implementation of the SEEK model.

Although we compared the rates of SNAP benefit receipt in the SEEK and control groups at the end of the SEEK study, it is possible that the maintenance of SNAP enrollment in the SEEK group was not due to SEEK involvement but due to intervention by other service agencies. While $81 \%$ of families completed follow-up assessments, and the demographic characteristics of families with and without follow-up were similar, unmeasured biases in retention or questionnaire completion may have led to finding a difference in SNAP enrollment at follow-up when none existed. For example, families with poor organizational skills or multiple stressors would be less likely to enroll in SNAP and also less likely to complete the follow-up assessment.
Despite these limitations, our single item FI screen is a promising addition to well child care, particularly for practices in low-income communities. With more than 12 million children living in food insecure households, [2] FI places a tremendous burden on both individual and societal health and productivity. Furthermore, the lack of progress toward the Healthy People 2020 goal of $6 \%$ of households with $\mathrm{FI}$ makes trying new approaches all the more important [37]. While most health care providers do not currently screen for FI, both family physicians and pediatricians express willingness to do so [38]. Large scale implementation of the $P S Q$ with an effective single $\mathrm{FI}$ screening question could benefit many children and families in the United States.

\section{CONCLUSIONS}

Given the prevalence and negative consequences of $\mathrm{FI}$ and the ease and potential benefits of screening, we recommend that screening should be a routine part of well child care, particularly for practices serving many low-income families.

\section{ACKNOWLEDGEMENTS}

This research was supported by a grants from the Office on Child Abuse and Neglect, Administration for Children, Youth, and Families, U.S. DHHS (90-CA1695) and the Eunice Kennedy Shriver National Institute of Child Health and Human Development, NIH (5K23 HD055515). We would like to thank Joshua Semiatin and Laurence Magder, PhD for their assistance with data analysis and interpretation.

\section{FINANCIAL DISCLOSURE}

No financial disclosures were reported by the authors of this paper.

\section{CLINICAL TRIAL REGISTRATION}

A Safe Environment for Every Kid (SEEK). ClinicalTrials.gov Identifier: NCT00507299. Date of registration: July 25, 2007. Funding source for trial Office on Child Abuse and Neglect, Administration for Children, Youth, and Families, U.S. DHHS (90-CA1695). University of Maryland Human Research Protections Office Approval, 2003.

\section{REFERENCES}

[1] United States Department of Agriculture, Economic Research Service. Food Security in the U.S.: Overview. April 30, 2014. Online at: http://www.ers.usda.gov/topics/food-nutrition- 
assistance/food-security-in-the-us.aspx\#.U5B6CfldWoM. Accessed June 4, 2014.

[2] Coleman-Jensen A, McFall W, Nord M. Food Insecurity in Households with Children: Prevelance, severity, and household characteristics, 2010-2011. Economic Research Service, Economic Information Bulletin 2013; 113.

[3] Cook JT, Frank DA, Berkowitz C, et al. Food insecurity is associated with adverse health outcomes among human infants and toddlers. J Nutr 2004; 134: 1432-8.

[4] Alaimo K, Olson CM, Frongillo EA. Food insufficiency, family income, and health in US preschool and school-age children. Am J Public Health 2001; 91; 781-6. http://dx.doi.org/10.2105/AJPH.91.5.781

[5] Weinreb L, Wehler C, Perloff J, et al. Hunger: its impact on children's health and mental health. Pediatrics 2002; 110: e41. http://dx.doi.org/10.1542/peds.110.4.e41

[6] Rose-Jacobs R, Black MM, Casey PH, et al. Household food insecurity: associations with at-risk infant and toddler development. Pediatrics 2008; 121: 65-72. http://dx.doi.org/10.1542/peds.2006-3717

[7] Jyoti D, Frongillo E, Jones S. Food insecurity affects school children's academic performance, weight gain, and social skills. J Nutr 2005; 135: 2831-9.

[8] Slopen N, Fitzmaurice G, Williams DR, Gilman SE. Poverty, food insecurity, and the behavior for childhood internalizing and externalizing disorders. J Am Acad Child Adolesc Psychiatry 2010; 49: 444-52.

[9] Alaimo K, Olson C, Frongillo E. Family food insufficiency, but not low family income, is positively associated with dysthymia and suicide symptoms in adolescents. J Nutr 2002; 132: 71925.

[10] Zaslow M, Bronte-Tinkey J, Capps R, et al. Food security during infancy: implications for attachment and mental proficiency in toddlerhood. Matern Child Health 2009; 13: 6680.

http://dx.doi.org/10.1007/s10995-008-0329-1

[11] Carmichael SL, Yang W, Herring A, et al. Maternal food insecurity is associated with increased risk of certain birth defects. J Nutr 2007; 137: 2087-92.

[12] Borders AEB, Grobman WA, Amsden LB, Holl JL. Chronic stress and LBW neonates in a low income population of women. Obstet Gynecol 2007; 109: 331-8. http://dx.doi.org/10.1097/01.AOG.0000250535.97920.b5

[13] Dubowitz H, Feigelman S, Lane W, Kim J. Pediatric primary care to help prevent child maltreatment: The Safe Environment for Every Kid (SEEK) Model. Pediatrics 2009; 123: 858-64. http://dx.doi.org/10.1542/peds.2008-1376

[14] Price C, Hamilton WL, Cook JT. Household food security in the United States in 1995: Guide to implementing the core food security module. Report prepared for the USDA Food and Consumer Service, Alexandria, VA 1997.

[15] Bickel G, Nord M, Price C, Hamilton W, Cook J. Guide to Measuring Household Food Security: Revised 2000. Alexandria, VA: US Department of Agriculture, Food and Nutrition Service; 2000. Available at: www.fns.usda.gov/ fsec/files/fsguide.pdf. Accessed.

[16] Hamilton WL, Cook JT, Thompson WW, et al. Household Food Insecurity in the United States in 1995: Summary Report of the Food Security Measurement Project. Alexandria, VA: US Department of Agriculture, Food and Consumer Service; 1997.

[17] Hamilton WL, Cook JT, Thompson WW, et al. Household Food Security in the United States in 1995: Technical Report. Alexandria, VA: US Department of Agriculture, Food and Consumer Service; 1997.
[18] Dubowitz H, Feigelman S, Lane WG, Prescott L, Blackman K, Grube L, Meyer W, Tracy JK. Screening for depression in an urban pediatric primary care clinic. Pediatrics 2007; 119: 435-43.

http://dx.doi.org/10.1542/peds.2006-2010

[19] Lane WG, Dubowitz H, Feigelman S, Kim J, Prescott L, Meyer W, Tracy JK. Screening for substance abuse in pediatric primary care. Ambulatory Pediatrics 2007; 7: 458462.

http://dx.doi.org/10.1016/j.ambp.2007.07.007

[20] Dubowitz H, Prescott L, Feigelman S, Lane W, Kim J. Screening for intimate partner violence in an urban pediatric primary care clinic. Pediatrics 2008; 121: e85-91. http://dx.doi.org/10.1542/peds.2007-0904

[21] Kim JK, Dubowitz H, Hudson-Martin E, Lane W. Comparison of Three Data Collection Methods for Gathering Sensitive and Non-sensitive Information. Ambulatory Pediatrics 2008; 8: $255-260$

\section{http://dx.doi.org/10.1016/j.ambp.2008.03.033}

[22] Feigelman S, Dubowitz H, Lane W, Prescott L, Meyer W, Tracy JK, Kim J. Screening for harsh punishment in a pediatric primary care clinic. Child Abuse Negl 2009; 33: 269-77.

http://dx.doi.org/10.1016/j.chiabu.2008.09.011

[23] Feigelman S, Dubowitz H, Lane W, Grube L, Kim J. Training pediatric residents in a primary care clinic to help address psychosocial problems and prevent child maltreatment. Academic Pediatrics 2011; 11: 474-480. http://dx.doi.org/10.1016/j.acap.2011.07.005

[24] Kleinman RE, Murphy M, Wieneke KM, et al. Use of a singlequestion screening tool to detect hunger in families attending a neighborhood health center. Ambulatory Pediatrics 2007; 7: $278-84$ http://dx.doi.org/10.1016/j.ambp.2007.03.005

[25] Hager ER, Quigg AM, Black MM. Development and validity of a 2-item screen to identify families at risk for food insecurity. Pediatrics 2010; 126: e26.

http://dx.doi.org/10.1542/peds.2009-3146

[26] Cohen JA. A coefficient of agreement for nominal scales. Educ Psychol Meas 1960; 20: 37-46. http://dx.doi.org/10.1177/001316446002000104

[27] Cutts DB, Pheley, AM, Geppert JS. Hunger in Midwestern inner-city young children. Arch Pediatr Adolesc Med 1998; 152: 489-493.

http://dx.doi.org/10.1001/archpedi.152.5.489

[28] Burkhardt MC, Beck AF, Kahn RS, Klein MD. Are our babies hungry? Food insecurity among infants in urban clinics. Clinical Pediatrics 2012; 51: 238-243. http://dx.doi.org/10.1177/0009922811426767

[29] Yen ST, Andrews M, Chen Z, Eastwood DB. Food Stamp Program participation and food insecurity: an instrumental variables approach. Am J Agr Econ 2008; 90: 117-132. http://dx.doi.org/10.1111/j.1467-8276.2007.01045.x

[30] Wise PH. Children of the recession. Arch Pediatr Adolesc Med 2009; 163: 1063-4.

http://dx.doi.org/10.1001/archpediatrics.2009.199

[31] Devaney BL, Ellwood MR, Love JM. Programs that mitigate the effects of poverty on children. Future Child 1997; 7: 88112.

http://dx.doi.org/10.2307/1602389

[32] DePolt R, Moffitt RA, Ribar D. Food Stamps, Temporary Assistance for Needy Families and food hardships in three American cities. Pacific Econ Rev 2009; 14: 445-473. http://dx.doi.org/10.1111/i.1468-0106.2009.00462x

[33] Neault N, Cook JT, Morris V, Frank DA. Boston Medica Center Department of Pediatrics. The real cost of a healthy diet: Healthful foods are out of reach for low-income families in Boston, Massachusetts. Children's HealthWatch. Published August, 2005. 
[34] Breen A, Cahil R, Ettinger de Cuba S, Cook J, Chilton M. The real cost of a healthy diet. Children's HealthWatch. Published November, 2011.

[35] Wiecha JL, Palombo R. Multiple program participation: Comparison of nutrition and food assistance program benefits with food costs in Boston, Massachusetts. Am J Public Health 1989; 79: 591-4.

http://dx.doi.org/10.2105/AJPH.79.5.591

[36] Melchior M, Caspi A, Howard I, et al. Mental health context of food insecurity: a representative cohort of families with young children. Pediatrics 2009; 124: e564.

http://dx.doi.org/10.1542/peds.2009-0583
[37] U.S. Department of Health and Human Services. Healthy People 2020. Nutrition and Weight Status. Washington, DC 2014. Online at: http://www.healthypeople.gov/2020/ topicsobjectives2020/overview. aspx?topicid=29. Accessed April 14, 2014.

[38] Hoisington AT, Braverman MT, Hargunani DE, Adams EJ, Alto CL. Health care providers' attention to food insecurity in households with children. Preventive Medicine 2012; 55: 219-222.

http://dx.doi.org/10.1016/j.ypmed.2012.06.007 